\title{
N. Cronk, Voltaire. A Very Short Introduction
}

\section{Debora Sicco}

\section{(2) OpenEdition}

\section{Journals}

\section{Edizione digitale}

URL: http://journals.openedition.org/studifrancesi/10572

DOI: 10.4000/studifrancesi. 10572

ISSN: 2421-5856

\section{Editore}

Rosenberg \& Sellier

\section{Edizione cartacea}

Data di pubblicazione: 1 décembre 2017

Paginazione: $549-550$

ISSN: 0039-2944

Notizia bibliografica digitale

Debora Sicco, «N. Cronk, Voltaire. A Very Short Introduction», Studi Francesi [Online], 183 (LXI | III) | 2017. online dal 01 février 2018, consultato il 21 janvier 2021. URL: http://journals.openedition.org/ studifrancesi/10572 ; DOI: https://doi.org/10.4000/studifrancesi.10572

Questo documento è stato generato automaticamente il 21 janvier 2021.

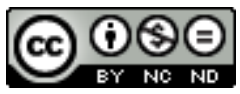

Studi Francesi è distribuita con Licenza Creative Commons Attribuzione - Non commerciale - Non opere derivate 4.0 Internazionale. 


\title{
N. Cronk, Voltaire. A Very Short Introduction
}

\author{
Debora Sicco
}

\section{NOTIZIA}

NichOLAS CRONK, Voltaire. A Very Short Introduction, Oxford, Oxford University Press, 2017, $151 \mathrm{pp}$.

1 In questa introduzione, di agevole (e gradevole) lettura, Nicholas Cronk ripercorre rapidamente le tappe salienti dell'esperienza e dell'opera di Voltaire, mostrando come la sua versatilità sia alla base della sua duratura influenza non solo in ambito letterario e filosofico, ma anche nel campo della politica e dei valori dell'intero occidente. Se ci si richiama alla sua autorità da diversi fronti politici, la sua eredità è particolarmente viva e presente negli attuali dibattiti sulla tolleranza. L'affissione in Boulevard Voltaire di un manifesto che lo ritrae insieme allo slogan «je suis Charlie» dopo l'attacco terroristico del gennaio 2015 testimonia efficacemente la carica ideologica ed emotiva che a tutt'oggi emana da questo autore poliedrico.

Le biografie di Voltaire continuano a proliferare, ma non prendono come soggetto François Marie-Arouet, bensì Voltaire, l'autore, il personaggio che François-Marie Arouet ha inventato e scelto di interpretare; come Cronk stesso afferma verso la fine del volume, «this book has tried to tell the story of that invention» (p. 113). Voltaire, infatti, si inventa e si reinventa costantemente, adattandosi di volta in volta alle circostanze: è un uomo di teatro, un poeta epicureo, un "inglese", uno scienziato, un cortigiano, un ginevrino, un attivista e una celebrità. La lista si potrebbe anche allungare, ma da questi ruoli non si può prescindere e, fra tutti, il primo è probabilmente quello più significativo, perché in qualche modo spiega e include gli altri: «More than a man of theatre, Voltaire is perhaps a master of theatrical performance, and this powerful sense of theatricality is central to all his literary performances» (p. 17). 
3 Voltaire è il solo fra i philosophes a servirsi tanto dei versi quanto della prosa per trasmettere le sue idee. Tuttavia, a partire dalle Lettres philosophiques del 1734 fino alle Questions sur l'Encyclopédie, il suo ultimo capolavoro, si è affermato sempre più come un grande scrittore di prosa. Il suo stile, caratterizzato dalla concisione, dall'ironia, dal gusto per l'aneddoto, è inconfondibile e innovativo, lontanissimo dalla pomposità della prosa del XVII secolo. Queste qualità sono quelle per cui lo leggiamo e lo ricordiamo oggi, anteponendo senza riserve un'opera come Candide alle tragedie o al poema epico da cui egli si attendeva la gloria letteraria.

4 Quando scrive Candide, Voltaire ha rinunciato a ogni velleità di cortigiano; dopo essersi in più occasioni scontrato con l'autorità, egli ha infine compreso che l'indipendenza garantita dal benessere economico è il modo migliore per esercitare liberamente la propria vocazione di scrittore.

5 Questa indipendenza consente al "patriarca di Ferney" di assumere il ruolo di guida dell'opinione pubblica e di forgiare, in primis grazie al suo impegno nell'affaire Calas, un'immagine pubblica di sé destinata a rimanere nel tempo. Fiero di scrivere per agire, alla metafisica Voltaire preferisce i fatti (e la scienza sperimentale di Newton). Forse proprio per questo ha raramente lasciato indifferente il suo pubblico, continuando a essere idolatrato o demonizzato anche dopo la sua morte. 